\title{
DE GLOSA A LO IMBORRABLE: TRÂNSITOS ÍNTIMOS NA OBRA DE JUAN JOSÉ SAER
}

\section{FROMGLOSA TOLO IMBORRABLE: INTIMATE TRANSITS IN THE WORK OF JUAN JOSÉ SAER}

RESUMO: Este trabalho busca observar como se dá, em dois romances do escritor argentino Juan José Saer, o trânsito entre elementos intertextuais de uma obra que se caracteriza por uma radical coerência interna, que permite a leitura dos diferentes textos como peças de um texto único. Pretende, também, analisar como o recurso da narração e da descrição das caminhadas acaba por mover a estrutura interna de Glosa (1986) e Lo imborrable (1993), os romances em questão. Interessam, por fim, os aspectos que permitem entender a construção do espaço narrativo na obra de Saer, e os distintos artifícios da ficção utilizados nesse intento. Palavras-chave: Juan José Saer; literatura argentina; espaço narrativo.

ABSTRACT: This article attempts to observe how, in two novels by the Argentine writer Juan José Saer, the transit between intertextual elements of his work, characterized by a radical internal coherence, allows the reading of different texts as pieces of one single text. It also intends to analyze how the expedient of narration and description of the walks end up moving the internal structure of Glosa (1986) and Lo imborrable (1993). Finally, the aspects that allow the understanding of the construction of the narrative space in Saer's work, and the different artifices of fiction used in his attempt, are also a point of interest in this paper.

Keywords: Juan José Saer; Argentine literature; narrative space.

Em Lo imborrable, romance de Juan José Saer (1937-2005) publicado em 1993, o leitor acompanha os passos de Carlos Tomatis, narrador e personagem, durante três dias, e o começo de um quarto, pelas

${ }^{7}$ Doutorando em Letras - Teoria da Literatura na Pontifícia Universidade Católica do Rio Grande do Sul-PUC/RS 


\section{8 | Iuri Almeida Müller}

ruas de uma cidade invernal. A narrativa parece obedecer ao ritmo dos passos do personagem: utiliza as pausas na caminhada constante e sempre recomeçada para recuperar episódios da vida de Tomatis, jornalista e escritor, e assim recuperar um tempo passado. Quando, no entanto, os sapatos voltam a pisar as calçadas de uma cidade de desenho geométrico, os antecedentes, a história pregressa e os acontecimentos laterais voltam a ocupar um lugar momentaneamente secundário no romance, para que a caminhada e os eventos que se relacionam com esse deslocamento encontrem uma espécie de presente perfeito na narrativa. Lo imborrable oscilará, ao longo da sua estrutura, entre o que se lembra e o que se conta no estado presente da narração, com o apelo aos detalhes da percepção que caracteriza o projeto do escritor santafesino.

Os leitores de Juan José Saer, quando se deparam com Lo imborrable, podem compreender desde o primeiro parágrafo que o texto volta a se inscrever em uma construção mais ampla, que busca a unidade entre, principalmente, os romances, mas também no que diz respeito aos contos e poemas publicados pelo autor. Ainda que Lo imborrable, como qualquer outro texto que se queira escolher, possa ser lido, por certo, de modo independente e desprendido de um conjunto que permite a leitura em perspectiva, os indícios da formação do que críticos como Julio Premat chamam de uma "novela familiar" levada adiante (PREMAT, 2002) se tornam mais visíveis e mais concretos, e permitem uma leitura única.

Em Lo imborrable, texto que se insere entre os últimos publicados pelo autor, o todo saeriano já tem suas bases claramente construídas: a novela se situará em um espaço narrativo que obedece à continuidade de uma geografia da ficção desenhada desde os primeiros relatos, datados dos anos 1960, e se ocupará de personagens igualmente conhecidos do leitor que segue os desenvolvimentos desta obra em processo; Carlos Tomatis, aqui narrador e protagonista, escritor e caminhante, já tem, por exemplo, um rosto e umas quantas ideias projetadas há longos anos e diversos textos. $\mathrm{O}$ mesmo pode ser dito das preocupações que movem a trama e a estrutura do romance: a importância concedida à reflexão literária, o espaço aberto para a indagação metafísica, traços de um humor satírico e olhos abertos para o que pode ser descrito como os aspectos da história externos à obra literária.

Em La dicha de Saturno, Julio Premat menciona quais seriam as propriedades mais visíveis e constantes da ficção do autor argentino: 
De Glosa a Lo imborrable: trânsitos íntimos na obra de Juan José Saer | 49

las tres características más espectaculares de la obra de Saer [...], [son,] primero, la coherencia espacio-temporal, temática y afectiva que remite entre líneas a un elemento inicial fuera de alcance y al objetivo de una unidad imperiosa; luego, la intensidad de lo pulsional y sensible, tanto en relación con el cuerpo y la sexualidad como con la percepción y la materia; y por último, la omnipresencia, en alguna medida contradictoria con lo anterior, de un autotematismo que lleva a transformar cualquier elemento en reflexión o imagen del proceso de creación literaria (PREMAT, 2002, p. 19).

Os traços acima mencionados são latentes em Lo imborrable; a "intensidade do que é pulsional e sensível" acompanha a breve temporada de um personagem que, para destacar de antemão as eventualidades mais destacadas do texto, se desloca do que ele mesmo, também narrador, chama de "o último degrau" da depressão da qual padece, para a lenta recuperação do desejo e da ação. Quanto à presença, sem dúvidas autorreferencial, da criação literária como preocupação interna da narrativa, a busca do personagem pela lenta retomada da escritura e a irrupção, no centro da narrativa, da leitura de um texto alheio, texto que será pormenorizadamente criticado e anotado, preenchem outra vez os elementos elencados na referência crítica e retomam o procedimento da intertextualidade como mediação da representação do real. Mas é a primeira das características apontadas por Premat - a coerência espaçotemporal e a unidade imperiosa na obra de Saer - que orientam o desdobramento proposto por esta leitura.

Ocorre que Lo imborrable surge, no contexto do sistema proposto pelo autor, como a continuidade possível de Glosa, romance publicado em 1986 e espécie de "claraboia" da obra de Saer, texto através do qual se podem observar as diferentes ramificações da coerência espaço-temporal que reside nesse projeto narrativo; Lo imborrable começa onde Glosa se permite encerrar, e ambos os textos, como se verá em detalhe a seguir, se situam na segunda metade do século $\mathrm{XX}$, quando analisamos sua delimitação histórica. De Glosa a Lo imborrable, serão visíveis algumas sortes de deslocamentos e continuidades: a geométrica caminhada que se pode ler no texto de 1986 espelhará, na mesma cidade, pelas mesmas ruas, a algo errante deambulação de 1993, com a repetição de vários dos nomes próprios (com Carlos Tomatis entre os mais destacados do "elenco 
estável" da obra saeriana) e a permanência de preocupações estéticas e estruturais - como seguir desenhando uma zona na qual se movem os textos, como levar ao corpo da ficção a reflexão sobre a escritura, como pleitear o tratamento do tempo em uma literatura já tocada, em seu século, pela dúvida, a experimentação e o rechaço do realismo convencional.

Nesta leitura, se pretende observar como os duplos deslocamentos de Glosa e Lo imborrable no todo saeriano (deslocamentos de um texto a outro; deslocamentos do narrador-personagem pela cidade, a mover o texto do romance) se inscrevem em uma discussão possível sobre as relações entre espaço e tempo no interior da obra. Escreve Julio Premat, no já mencionado estudo, que, por aquele então (La dicha de Saturno foi finalizado em 2002), a obra de Saer permanecia sendo relativamente pouco lida, mesmo na Argentina, em constatação que, sem dúvida, se estende aos demais países do continente:

Tautológicmente, Saer resulta poco legible porque no se lee (o no se lo ha leído). No hay que olvidar, tampoco, la amplitud del corpus: dieciséis libros de ficción, cuatro volúmenes de ensayo, uno de poesía, a lo largo de cuarenta años de escritura [...], lo que supone, dentro de la estrategia de amplificación, reescritura, autointerpretación, dispersión y modificación de un único texto, que cada etapa, que cada libro, propone una nueva perspectiva sobre el conjunto, abre una nueva lectura de lo ya escrito (PREMAT, 2002, p. 14).

Mais de uma década depois, o estado crítico da ficção de Saer já não é o mesmo, e se pode dizer que seus romances, reeditados e reimpressos, traduzidos para diversos idiomas, encontraram mais leitores, críticos e pesquisadores, mesmo que certa aura de "hermetismo" e "lentidão", frequentemente atribuída aos textos, permaneça a emperrar alguns diálogos. Seja como for, parece válido voltar a dizer, a cada início de contato com essa ficção, que o texto de Saer, sempre que tocado, já parece outro, como provam as palavras escolhidas por Premat e recolhidas na citação acima: amplificação, dispersão, modificação - não apenas para a escritura, mas também para os registros do leitor e da leitura crítica dessa obra.

Para este momento, interessam aqui, em particular, os deslocamentos de Lo imborrable, os trânsitos que a narrativa estabelece 
com Glosa e outros dos textos do autor, o tratamento do tempo presente e as caminhadas de Carlos Tomatis pela cidade nunca nomeada, e que se instalam em uma potente discussão política sobre a história e a memória da Argentina.

São bem conhecidas, no contexto da crítica dirigida à obra de Saer, as frases que inauguram o texto de Glosa, e que por sua brevidade podem ser recuperadas aqui: "Es, si se quiere, octubre, octubre o noviembre, del sesenta o del sesenta y uno, octubre tal vez, el catorce o el dieciséis, o el veintidós o el veintitrés tal vez, el veintitrés de octubre de mil novecientos sesenta y uno pongamos [...]" (SAER, 1995, p. 13). A abertura do romance começa por tornar visível a exigência de se definir uma data, a temporalidade do começo do texto, passa à oscilação sobre essa data (outubro ou novembro, mil novecentos e sessenta ou sessenta e um, dia vinte e dois ou vinte e três, etc.) e, por fim, decide-se por um marco temporal para o que será narrado a partir de então. Quase que por convenção, Ángel Leto e o Matemático, os dois personagens centrais para Glosa, precisam de uma localização temporal no calendário para que caminhem, os dois, não com o mesmo objetivo, como se verá, pelas ruas que serão então as ruas de outubro de 1961.

Se o narrador orienta Glosa, depois de certa hesitação, em determinada data (e essa aparente fragilidade da demarcação temporal se atenua depois do posicionamento inicial), será justamente em relação a este começo e às frases recordadas acima que Lo imborrable se dirigirá, anos mais tarde, em outra sorte de começo. Na abertura de Lo imborrable, romance publicado sete anos depois de Glosa, lê-se: "Pasaron, como venía diciendo hace un momento, veinte años: anochece" (SAER, 2003, p. 9). Passaram-se vinte anos, e ainda que a referência não se instale, de imediato, no parágrafo de abertura, a estrutura e os acontecimentos narrados no texto mostrarão a que se refere essa passagem: Lo imborrable, no âmbito interno da temporalidade saeriana, começará, já se disse, vinte anos depois de Glosa.

Passaram-se vinte anos da caminhada de Leto e o Matemático pela cidade; este é o ponto de partida de Lo imborrable, que levará adiante outra caminhada, e que pode ser situada no começo dos anos 1980 - em meio à ditadura militar argentina. A delimitação temporal de Lo imborrable ficará evidente páginas depois, quando Tomatis, narrador e personagem, estabelece o primeiro contato com Alfonso, distribuidor de livros naquela província, personagem com quem dialoga e que o 


\section{2 | Iuri Almeida Müller}

acompanha nas breves jornadas aqui narradas: "Según Alfonso, tiene ganas de conocerme desde hace mucho y, cinco o seis años atrás, por el setenta y cuatro más o menos, cuando extendió la distribuidora al norte de la provincia y a Entre Ríos, pensó en proponerme la dirección de la nueva zona (SAER, 2003, p. 14).

Há, ainda, outra relação que se estabelece entre o começo de Lo imborrable e o todo da obra de Saer, conjunto que, em razão da já mencionada coerência interna dos textos, pede, como propôs Julio Premat, por uma leitura única, ou que atente para a intertextualidade interna que liga e reúne os seus fragmentos. Trata-se do parágrafo inaugural de El limonero real, romance de 1974, tido como a experimentação mais radical do autor no que diz respeito aos limites a que se leva o manejo da linguagem e o tratamento formal, ao menos no que se restringe aos romances. $\mathrm{O}$ "anochece" que tem lugar na narrativa invernal e noturna de Lo imborrable encontra, na primeira palavra de $E l$ limonero real, seu reverso diurno: "Amanece" (SAER, 2006, p. 11) é o que se lê no ponto de partida do texto de 1974, em associação que pode ser expandida e não pretende ser esmiuçada, por agora, neste trabalho.

Foi dito que o arco temporal que começa em Glosa alcança o presente de Lo imborrable; no entanto, não se pode dizer que, textualmente, o segundo texto prolonga, em continuidade inalterada, o primeiro. Isso porque o trânsito entre um e outro romance ocorre com significativas alterações, e o deslocamento impõe perdas, transformações, acréscimos de propriedades novas. Se o espaço geográfico é o mesmo, e a geografia da cidade simétrica se mantém, não se conservam, por outro lado, os protagonismos (Leto e o Matemático, caminhantes na narração que se passa em 1961, não são mencionados em Lo imborrable, cujo protagonismo cabe individualmente a Carlos Tomatis) e tampouco as condições do narrador (o narrador de Glosa, situado em uma distância da narrativa que por vezes se parece onettiana ${ }^{8}$, abre espaços para o passado e o futuro da obra de Saer, enquanto que o de Lo imborrable se restringe à

${ }^{8} \mathrm{Da}$ introdução, assinada por Juan José Saer, à edição crítica de Novelas cortas, de Juan Carlos Onetti (1909-1994): "El narrador, por ejemplo, en casi todos sus textos, más allá de las académicas atribuiciones del punto de vista, siempre tiene una posición, una distancia, una capacidad de percibir y de comprender respecto de lo narrado que es diferente cada vez y únicamente válida para el relato al que se aplica” (2009, p. XVI). 
De Glosa a Lo imborrable: trânsitos íntimos na obra de Juan José Saer | 53

visão e à percepção de Tomatis e ao tempo presente, mesmo que com pontuais fissuras e eventuais recuos).

Em "La condición mortal”, texto de 1993, escrito após a primeira aparição de Lo imborrable na Argentina, e posteriormente incluído em Escritos sobre literatura argentina, escreve Beatriz Sarlo: "las veitiún cuadras recorridas [em Glosa] son tiempo y espacio que se parcelan para que entren outros tiempos futuros, en otros espacios diferentes: entre un extremo y otro [...] se incrustan anchas franjas del mundo narrativo de Saer" (2007, p. 291). Entre as aberturas para o tempo futuro em Glosa, possibilitadas por esta narração situada mais além do puro presente, se encontram revelações sobre o destino de alguns dos personagens constantes do conjunto do autor, como é o caso da revelação sobre a morte do próprio Ángel Leto que, na ditadura que ainda não se vislumbra com nitidez no horizonte temporal quando da caminhada de 1961, se juntará à resistência armada, e o desaparecimento de Gato Garay e Elisa, protagonistas de Nadie nada nunca, romance de Saer publicado em 1980. Para Beatriz Sarlo,

en el párrafo breve y severo de Glosa, se clausuraban tres destinos que hasta entonces [...] estaban abiertos. En una obra que nunca ha desmentido su radicalidad estética y cuya perfección se funda en la coherencia de la experimentación narrativa, de pronto, como un golpe de timbales que se destaca por su brevedad de relámpago, el pathos de la probable muerte del Gato [Garay] y Elisa, de la segura muerte de Ángel Leto, irrumpe clausurando una historia que es anterior a Glosa. (SARLO, 2007, p. 292)

Quanto a Carlos Tomatis, seu destino, ou ao menos um fragmento dele, também se deixa entrever na observação panorâmica de Glosa, e se trata, como se verá a seguir, de um destino menos trágico. Mas onde se situa a presença de Tomatis em Glosa? Carlos não tece a caminhada pela avenida San Martín com Leto e o Matemático; é encontrado por acaso, e esse encontro fortuito é também uma interrupção: trata-se do instante em que a narrativa se detém por mais tempo, e que suspende o trajeto aparentemente linear que levam adiante os dois caminhantes. Dividido em três partes, também elas carregadas de simetria, o romance mostrará Tomatis no capítulo intitulado "Las siete cuadras siguientes", posterior a "Las primeras siete cuadras" e, por 


\section{4 | Iuri Almeida Müller}

continuidade, anterior a "Las últimas siete cuadras", no centro possível da arquitetura de Glosa.

Com Leto e o Matemático, Tomatis dividirá tão somente alguns metros de caminhada. Antes, é evocado algumas vezes, visto que estabelece relação com os dois personagens e com alguns dos eventos desenvolvidos na trama. Quando, logo no início da caminhada de Leto, gesto que move a estrutura do texto quando rechaça a ida diária ao escritório e se põe, sem motivo aparente, a caminhar pela cidade, o Matemático é avistado, Leto recorda a opinião de Tomatis sobre o homem alto, sempre bem-vestido e, para o grupo de amigos, dono da estranha predileção pelas ciências exatas. "Ya ha sido Tomatis, por otra parte, según le ha oído decir Leto ya no se sabe a quién, el que ha empezado a llamarlo el Matemático. No es un mal tipo, no, dice a menudo, un poco snob a lo sumo" (SAER, 1995, p. 14), lê-se ainda no que diz respeito às primeiras sete quadras.

$\mathrm{Na}$ sequência, já na segunda das partes do romance, Carlos Tomatis é encontrado em frente à sede do jornal La Región, em que trabalha (ofício e emprego reiteradamente mencionados ao longo da obra de Saer), e esse encontro que interrompe a caminhada acaba por estabelecer a maior das pausas que têm lugar na narrativa. Tomatis, como que alheio à tarde de outubro e de amargo humor, divide com os dois caminhantes frases dispersas e desinteressadas; parece adquirir algum vigor apenas quando decide ler, diante de Leto e o Matemático, alguns dos versos que havia composto naquele mesmo dia. Recita Tomatis: "En uno que se moría / mi propia muerte no vi, / pero en fiebre y geometría / se me fue pasando el día / y ahora me velan a mí" (SAER, 1995, p. 131), e esses versos, de forma alguma casuais, se acomodarão também em outra função no romance, visto que aparecem como a epígrafe que inaugura Glosa, ainda sem a indicação do personagem-autor do poema, e que, no que se refere ao enredo, após a leitura, e a pedido do Matemático, repousarão em papel no bolso do amigo.

Os cinco versos não abandonam o texto depois do encontro casual com Tomatis e da mudança, quem sabe inesperada, de endereço, da propriedade de Tomatis para o bolso do Matemático; o que ocorre é o revés, já que o novo proprietário entrega ao papel a enigmática função de amuleto. Será a folha datilografada com os cinco versos o elemento que Glosa se utiliza para levar o texto ao futuro dos personagens, para pressionar o arco da temporalidade para mais adiante, frear a narração do tempo presente e inserir um novo tempo e um novo espaço. $O$ primeiro 
De Glosa a Lo imborrable: trânsitos íntimos na obra de Juan José Saer | 55

salto temporal, em relação ao destino do Matemático e à sobrevivência do poema, pode ser lido assim:

el Matemático que, una mañana de mil novecientos setenta y nueve, a bordo de un avión que viene desde París y que empieza a bajar hacia el aeropuerto de Estocolmo, mientras espera, paciente, el aterrizaje, saca la billetera del bolsillo y, de entre los billetes, las tarjetas de crédito, las credenciales, retira la hoja doblada en cuatro que Tomatis le regaló en la puerta del diario, la hoja cuyos dobleces ya están más marrones que amarillos. (SAER, 1995, p. 148)

Logo adiante, se dirá que o Matemático sequer volta a ler os cinco versos, e que a folha já perdeu o seu caráter de mensagem "para volverse objeto y, sobre todo, reliquia" (1995, p. 148); "o vestigio, más bien, no de Tomatis [...] sino de la mãnana em que, acabando de volver de su primer viaje a Europa, se encontró con Leto en la calle principal y caminaron juntos hacia el Sur (1995, p. 149). Caberá à folha, a folha com os cinco versos de início imaginados, logo escritos, e então presenteados, a tarefa de estreitar os tempos do romance, levar, por meio das mãos do Matemático, os personagens para um tempo futuro: um tempo que carregará também as marcas das transformações políticas e históricas da Argentina.

Neste tempo posterior ao presente de Glosa, a ficção de Saer permite que se enxergue, a partir do texto de 1986, e de maneira bastante crua, algumas vítimas entre o elenco de personagens; mas, se Leto, Gato Garay e Elisa se deparam com a "condição mortal" a que se refere Beatriz Sarlo, ao Matemático caberá a sobrevivência no exílio, como comprova o trecho citado anteriormente, Tomatis é, por sua vez, quem pode escapar do desterro e do desaparecimento. Entre os nomes próprios que habitam o centro de Glosa, é Tomatis o único a permanecer e sobreviver: apagados os rastros de Elisa e do Gato, constatado o fim trágico e violento de Leto, obrigatoriamente desterrado o Matemático, Tomatis seguirá na cidade, e é a história desta permanência e desta sobrevivência o que se conta em Lo imborrable, o romance que Saer entrega aos leitores sete anos depois.

Sobrevivente e persistente habitante da cidade, da zona saeriana, Tomatis também terá o seu destino, ou um fragmento de destino, antecipado nas páginas finais de Glosa. Na terceira e última das suas partes, o romance trata de narrar, no tempo futuro que se pode situar, na 


\section{6 | Iuri Almeida Müller}

narrativa, entre os últimos instantes dos anos 1970 e os primeiros da década nova, em meio às notícias de desaparecimentos políticos, exílios forçados, da crise econômica e social que promove a ditadura argentina, o encontro entre Leto e Tomatis, justamente na casa a que esse último retornou (a casa materna) após o seu terceiro divórcio, casa que será, depois, um dos espaços recorrentes de Lo imborrable. Lê-se, a partir da percepção e da antecipação do narrador de Glosa: "[Leto] irá a visitar Tomatis a la casa de su madre, en la que se habrá refugiado después de su tercer divorcio. En esos tiempos Tomatis estará sufriendo de eso que los psiquiatras llaman una depresión" (SAER, 1995, p. 273). Estado anímico que, a sequência do texto desenha, será temporário, mas que naquele então se encontrava em seu ponto mais crítico.

Esse estreitamento do tempo em Glosa, a aproximação da tarde de outubro de 1961 com os acontecimentos de duas décadas mais tarde, mostra a possibilidade de radicalização dos primeiros deslocamentos. Leto visita Tomatis porque entende que, a partir de então, serão raras as chances de encontrar o amigo novamente; Tomatis parece viver uma sucessão de dias idênticos, em frente ao aparelho de televisão, dias que são também de rechaço do mundo exterior; e o Matemático, que não se encontra mais no mesmo território, que guardou o papel com os versos que falam de "fiebre y geometría" já caminha pelas ruas de outro continente. Mas, depois de se observar como se dá esse deslocamento, esse ponto de inflexão no conjunto dos personagens de Saer, o leitor pode se perguntar se o destino desses personagens já residia (em nítida forma, ou em sutil aparição, quem sabe) nas primeiras páginas daquela caminhada. O que também seria perguntar, com outras palavras: de que modo a política se fazia presente desde a abertura do romance?

Martín Kohan propõe a leitura de Glosa como um romance político, além de afirmar que o texto de 1986 pode ser visto como uma peça de culminação e condensação (KOHAN, 2011, p. 151) da obra de Saer. Kohan recorda que a caminhada do Matemático tem como objetivo, mencionado de antemão, entregar comunicados da organização de estudantes a que pertence, e a vinculação com a militância política, em mais de um momento da narrativa, é relacionada com os riscos que um posicionamento como o do Matemático acarretaria já naquela etapa dos anos 1960. Não se trata, porém, ao menos não em Glosa, e não em Saer, de pensar a literatura e o texto de ficção como representação direta e sem fissuras de uma realidade política - e essa é a mais nítida defesa do texto de Martín Kohan sobre Glosa. 
De Glosa a Lo imborrable: trânsitos íntimos na obra de Juan José Saer | 57

"De Glosa misma, como novela, puede decirse que se ubica [...] entre la promesa de precisión de las palabras, que les permitirá decir lo que ha pasado, y la gozosa aceptación de que las palabras nunca cesarán de ser imprecisas" (KOHAN, 2011, p. 154), afirma o escritor e crítico argentino. A menção à oscilação entre a palavra precisa e a palavra que invariavelmente desvia e se dispersa, condição que determina as possibilidades da representação política na ficção de Saer, alude também a um aspecto de Glosa ainda não comentado aqui: ao longo do romance, um dos temas de conversação que invariavelmente retorna ao corpo do texto é a tentativa de recriar o que aconteceu na festa de aniversário de Washington Noriega (outro dos personagens sempre presentes, ou recordados, de Saer), festa a que nem Leto e nem o Matemático puderam comparecer. A reconstituição dos convidados presentes, dos assuntos de debate, da localização de cada um na chácara situada em Colastiné, localidade que recebeu a festa, os detalhes turvos da noite e mesmo os pratos de comida ali servidos são, em Glosa, reiteradamente postos em discussão, sob o aspecto da dúvida, e nem mesmo o encontro com alguém que, sim, esteve presente (como é o caso de Carlos Tomatis) pode dissipar a supremacia da versão sobre a certeza.

O enfrentamento constante entre a dúvida e a versão se apodera de outros núcleos de Glosa e, sob o signo da imprecisão e da desconfiança da representação da realidade no texto literário, se estende à política. Escreve Kohan que: "no se espera, no se pretende, que la literatura capture una realidad, que la aferre, que la plasme, que la despliegue, que la enseñe, y que con todo eso se elabore una consigna o una conclusión" (2011, p. 154), e na sequência dirá que a política, no romance, se escreve de outra maneira: "produciendo el destello de un para qué en medio de los para nada, produciendo el brillo de una referencia precisa en medio de un mar de imprecisón verbal y metaverbal” (2011, p. 154). É fácil corroborar o apontamento de Kohan: ainda que permaneçam sob a dúvida das chances de representação, as frases mais concisas, duras e de emprego denotativo são as que fazem referência, desta vez direta, ao destino trágico dos personagens atravessados pelo tempo político, como a morte de Leto em meio à resistência, o exílio do Matemático e a depressão, amplificada pelos acontecimentos recentes e exteriores ao próprio corpo, de Carlos Tomatis.

A partir daqui, pode-se dizer que Lo imborrable começa no momento em que Glosa se estende aos tempos futuros da antecipação e se adensa politicamente, conforme as ideias defendidas por Kohan. O início 
de Lo imborrable (o "Anochece", já mencionado, de uma jornada invernal na zona) é saída de Tomatis da imobilidade que o atinge no texto de 1986. Depois da visita (não reiterada discursivamente no romance de 1993) de Leto e da morte do amigo, depois da constatação de que o país convive com a notícia de assassinados e desaparecidos. Lo imborrable começa quando Carlos Tomatis pode dar os primeiros passos de volta para a rua, para então recomeçar novos deslocamentos e novas caminhadas; que, como se verá a seguir, serão caminhadas distintas e obedecerão a outras formas, mas que ainda estarão enfrentadas com a presença da política no texto literário e das tentativas de transpor essa presença à literatura.

Escreve Julio Premat, em La dicha de Saturno, sobre a estrutura de Glosa: "el paseo de los protagonistas se lleva a cabo entre el orden (el de la ciudad en damero, herencia de la urbanización lógica de los griegos) y el caos (las corrientes imprevisibles y amenazadoras de los coches que parecen acosarlos)" (2002, p. 245). A mesma oposição entre ordem e caos, entre caminhada simétrica e linear, e a errância do que é irrefletido, aparece no já mencionado ensaio de Martín Kohan, que localiza a dualidade não entre os aspectos da cidade, como propõe Premat (o esquema geométrico diante da desordem do trânsito), mas em relação aos próprios caminhantes: "Ángel Leto camina sin un objetivo; el Matemático, no” (2011, p. 147). Para Kohan, esta diferença primordial acaba por definir as possibilidades do romance, esboçadas desde o primeiro passo.

Ángel Leto caminha motivado por uma força estranha, o impulso sem nome que o desviou do caminho do trabalho para levá-lo por uma das principais avenidas da cidade, como se pode ler no quarto parágrafo de Glosa: "El hombre que se levanta a la mañana, que se da una ducha, que desayuna y sale, después, al sol del centro, viene, sin duda, de más lejos que su cama, y de una oscuridad más grande y más espesa que la de su dormitorio" (SAER, 1995, p. 14). A continuação do mesmo trecho mostra que a motivação do deambular de Leto é misteriosa mesmo para o narrador em terceira pessoa daquele texto: "nada ni nadie en el mundo podría decir por qué Leto, esta mañana, en lugar de ir, como todos los días, a su trabajo, está ahora caminando, indolente y tranquilo [...] por San Martín hacia el Sur" (1995, p. 14). Para Leto, cabe a ausência de objetivo, a concessão ao fluxo; ao Matemático, a caminhada com motivação clara, a da entrega de comunicados à imprensa, o compromisso político. 
De Glosa a Lo imborrable: trânsitos íntimos na obra de Juan José Saer | 59

Kohan escreve que "esta diferencia de actitud, o de disposición, entre los dos personajes, [...] supone que las relaciones posibles entre caminata y narración, entre recorrido y escritura, no son necesariamente homogéneas" (2011, p. 147). O contraste entre os caminhantes, em Glosa, contraste que em algum momento alcançará a semelhança, visto que os passos dos caminhantes, depois de algumas quadras, encontram um ritmo comum (uma sincronia), poderá, na proposta de Kohan, se estender às possibilidades do ato político: assim se estrutura a caminhada em Glosa. Em Lo imborrable, no entanto, essa oposição entre ordem e caos não é representada da mesma maneira; para o romance que tem Carlos Tomatis como protagonista, a caminhada assume outras formas e desvenda novos sentidos no texto.

A narração orientada pela voz e o pensamento do próprio Tomatis (visto que é protagonista e narrador) acompanha o personagem por três dias e o começo de uma quarta jornada; ele, mais do que nada, realiza dois procedimentos, gestos que são internos em relação ao texto, mas que movimentam também a estrutura de Lo imborrable: Tomatis caminha, e Tomatis recorda, muitas vezes ao mesmo tempo. Para ele, a caminhada pela cidade nunca nomeada é uma espécie de retorno, de reencontro com um espaço que havia se tornado estranho, e que aos poucos volta a carregar consigo familiaridade:

"Yo" que hace unos pocos meses nomás no me atrevía a salir de mi casa para ir a tomar un café al bar de la galería por miedo de que la construcción endeble del supuesto firmamento se desplomara, y que tres o cuatro veces, después de haber atravesado con valentía el umbral y haber dado algunos pasos por la vereda, me volvía temblando de terror a mi cuarto de la terraza, diciéndome que nunca más podría volver a salir a la calle, me encuentro, en este anochecer de invierno, a cargo del universo [...] (SAER, 2003, p. 19).

A cidade a que Tomatis se expõe é, portanto, uma cidade parcialmente recuperada. Recuperada porque pode voltar a ela, depois dos meses de encerramento na casa materna, justamente os meses em que vê a mãe se enfraquecer e morrer, mas parcialmente porque essa não é a mesma cidade: a cidade saeriana de Lo imborrable não é a cidade de Glosa, ainda que esteja inscrita em um mesmo espaço narrativo. Não é a mesma 


\section{0 | Iuri Almeida Müller}

porque o tempo avança: no lugar da caminhada relativamente livre e despreocupada (ao menos de perigos iminentes) dos anos 1960, o andar agora se dá no coração de uma cidade invernal, noturna, de raros passantes pelas ruas, em uma atmosfera de melancolia e risco. Se, como sustenta Julio Premat, "la posición de Saer ante la realidad y ante la creación es una posición melancólica” (2002, p. 28), Lo imborrable seria dos exemplos mais nítidos desta posição.

As menções ao contexto da ditadura militar argentina são abundantes ao longo de todo o texto, e aparecem em construções diretas que contrastam com o estilo labiríntico e aberto à dúvida que pode ser visto em Glosa. No romance de 1993, são mencionados pelo narrador Carlos Tomatis, para ficar com três exemplos de rápida aparição no desenvolvimento do texto: o desaparecimento forçado de um casal de distribuidores de livros, pessoas que não teriam qualquer relação com a militância política (SAER, 2003, p. 14), os problemas que o próprio narrador poderia ter encontrado com a censura devido à publicação de uma crítica a um autor ligado ao regime (2003, p. 17) e a existência de um general e torturador, conhecido como o "carniceiro do Paraná", de sobrenome Negri (2003, p. 32).

As indicações acima elencadas parecem justificar o aspecto externo das ruas percorridas por Carlos Tomatis, frequentemente descritas como ruas vazias, escuras e perigosas. "La calle está casi desierta, a causa del frío, o de la hora, o de los tiempos que corren probablemente. Los habitantes de la ciudad, conscientes de la amenaza que representan aquellos por los que pretenden sentirse protegidos, me dejan la noche libre" (2003, p. 38), pode-se ler em um fragmento de Lo imborrable, em uma descrição algo desolada de um panorama urbano. Desolação que se repetirá ao longo do texto, como se vê no trecho a seguir: "A pesar de la hora [...] la calle está bastante desierta: el frío, la lluvia, la proximidad de la noche, la tiranía, quizás, las telenovelas probablemente, retienen a la gente en sus casas”. (2003, p. 185)

Embora o primeiro excerto pinçado acima corresponda ao primeiro dia da trajetória de Tomatis, e o segundo à noite da terceira jornada, a cidade que se enxerga desde os olhos do narrador é praticamente a mesma: espaço de ruas vazias, tomado pelo frio e por luzes difusas (as lâmpadas fracas da iluminação pública, o néon de alguma publicidade, o farol dos carros que passam) e sujeita à tirania dos "tempos que correm”. Há, no entanto, outras caminhadas, e outras visões de cidade, em Lo imborrable, e que obedecem também a olhares de Carlos 
De Glosa a Lo imborrable: trânsitos íntimos na obra de Juan José Saer | 61

Tomatis, como por exemplo a recordação da tarde em que se encontrou pela primeira vez com Haydée, sua ex-mulher, em um sábado de bom tempo e de trajetos que buscam a direção do rio. Mas mesmo as memórias luminosas estão, em Saer, como que manchadas, enfrentadas com a realidade. Nesse caso, em disputa com a dúvida que interroga a lembrança, e com o estranhamento que pressupõe retomar a experiência.

A recordação dos sábados de uma cidade luminosa, ao lado da pessoa amada, pode habitar a repetição dos dias, a ponto de colocar a singularidade da lembrança amorosa sob o manto da dúvida:

Me acuerdo que fue refrescando con el anochecer y que, a partir de cierto momento, empezamos a sentir frío en la penumbra de la costanera pero, a decir verdad, desde que tengo memoria, cuántos sábados soleados de otoño no terminaron refrescando al anochecer, y cuántas veces, en la penumbra de la costanera, paseando incluso con Haydée, no tuvimos frío al cabo de un momento? (SAER, 2003, p. 72)

Se, por um lado, a lembrança de uma cidade menos sombria pode ser enfrentada pela interrogação, por outro a estranheza dos instantes escolhidos e organizados pela experiência acabam por afastar qualquer descrição idealizada; é o caso da lembrança do primeiro encontro de Tomatis com Haydée, quando o narrador percebe que recorda não o momento em que a mulher aparece pela primeira vez, mas o aspecto lúgubre de um armazém de bebidas, no qual esperava pouco antes, e que resiste na memória com seus frequentadores desagradáveis diante do balcão. "Lo más real no es lo que queremos que lo sea, sino un orden material de nuestra experiencia que es indiferente a nuestras emociones y deseos (2003, p. 72), anota o narrador. Não há, nos espaços de Lo imborrable, espaços para a inocência.

Ainda assim, neste texto-chave para entender a "posição melancólica" que se opera na obra de Juan José Saer, o romance oferece também as suas aberturas; afinal, o que se narra é o retorno de Carlos Tomatis aos espaços urbanos, ainda que sombrios, da zona saeriana. Ao longo de pouco mais de três dias, o protagonista se encontrará com Alfonso e Vilma, os distribuidores de livros que acabarão por lhe oferecer um trabalho, voltará a visitar alguns dos pontos da cidade que costumava frequentar (o bar da galeria, o palomar), percorrerá a mencionada rua San Martín e as passagens que a cortam, visitará as dependências do hotel 


\section{2 | Iuri Almeida Müller}

Iguazú e, desta vez a bordo do carro de Alfonso, acompanhará os interlocutores até o aeroporto da cidade, distante da região central. Também o desejo, em sua motivação mais física, adormecido durante meses, logra seu retorno ao final da narrativa (2003, p. 240).

Em Lo imborrable, Tomatis recupera sua mobilidade, sem se afastar de todo da presença do que chama, repetidamente, de "o último degrau", a posição extrema da depressão: "Que me maten si cuando entreabro la puerta y veo la luz gris de la terraza, no me dan ganas de echarme atrás y de volver a meterme en la cama, taparme hasta la cabeza y quedarme encerrado el día entero en la penumbra del cuarto" (2003, p. 104), lê-se antes de uma das saídas do personagem à rua. Descartada antes a inocência, e rechaçada então também a naturalidade destes passos reiniciados, Carlos Tomatis ainda assim volta a caminhar, e percebe o gesto da caminhada como a possibilidade única de recuperação e de retorno.

Saer, ao transportar a narração do olhar onipresente e de certo modo distanciado de Glosa para a perspectiva atormentada de Carlos Tomatis em Lo imborrable, volta a preencher algumas das lacunas de um mesmo espaço. O que Beatriz Sarlo chama de "sucesión definida por microacontecimentos" (2007, p. 295) volta a se operar aqui, e ao final de Lo imborrable sabemos algo mais sobre Glosa, algo mais sobre Tomatis, precisamos rever, quem sabe, a leitura prévia de Nadie nada nunca, entre outros textos. Volta-se, enfim, a tocar o corpus saeriano, conjunto que se move enquanto um incessante recomeço da literatura.

Escreve Premat que "el espacio en la obra de Saer, más que compoener paisajes o conjuntos referenciales, más que servir de telón de fondo a estrategias realistas [...], aparece ante todo como un conjunto de substancias a la vez inestables y amenazantes" (2002, p. 180). O estudo do espaço, em La dicha de Saturno, também é observado desde o viés psicanalítico (que aborda, na primeira parte do texto, a relação dos personagens de Saer com os vínculos maternos e paternos) que aponta para a posição melancólica, abundante e definidora do conjunto. Mais do que isso, a escolha das palavras "instável" e "ameaçadora" para definir a construção desse espaço ajuda, também, a entender os deslocamentos aqui observados.

A cidade hostil de Lo imborrable, que se abre vazia para o recomeço amedrontado de Carlos Tomatis, não atinge o texto de Saer pela primeira vez; essa mesma cidade, a região urbana da zona a que o início desse trabalho fez referência, já havia se infiltrado instável e ameaçadora na 
narrativa em outros momentos, e mesmo para além dos romances. Célebre no conjunto do autor, o conto "A medio borrar", de La mayor (1976), mostra como a mesma cidade se enfrenta com uma prolongada e crescente inundação, que ameaça a permanência dos personagens, parece a ponto de derrubar a principal ponto de referência do lugar e marca, com água, os dias de despedida do personagem Pichón Garay, o irmão gêmeo do já mencionado Gato, que parte em definitivo da zona para a Europa em meio à enchente.

Já em Unidad de lugar, livro de contos publicado em 1967, é o revés da água, a seca, o fenômeno que assola a cidade saeriana: em "Fotofobia", em deslocamento análogo ao que efetua o narrador-personagem de Lo imborrable, uma caminhante tenta avançar pelas quadras calcinadas pelo sol do verão depois de dias de reclusão em casa. Peça do mesmo conjunto, "Barro cocido" narra uma situação de espera e reencontros nos arrabaldes da cidade em dias de terrível seca, ao lado da recordação, por parte dos personagens, de outras temporadas de seca e dilúvio que já haviam entrado para a história da região. Em La ocasión, de 1988, texto-chave para entender a formação da coerência espacial, temática e estrutural da obra de Saer, é a chegada da peste ao lugar que acaba por modificar a estrutura do espaço e forçar os deslocamentos dos personagens e as fissuras do texto.

Instável e ameaçador, como nos exemplos acima pinçados, aberto para as infiltrações temporais, do passado e do futuro, como em Glosa, desolado e invernal, como em Lo imborrable, o espaço narrativo é central, em Saer, para entender do que é feita a sua literatura. A importância dessa riquíssima geografia literária, erguida desde e para a ficção, também encontra sua correspondência em vários dos títulos escolhidos pelo autor: de En la zona, primeiro volume de contos, publicado ainda em 1960, a Lugar, conjunto de argumentos e relatos breves, de 2000, passando pelo semelhante Unidad de lugar.

Antes do fim, é preciso mencionar, ainda que de modo veloz, um dos problemas relacionados a esse espaço, e que atravessou toda a leitura analítica levada adiante desde o começo do texto: a semelhança, e a correspondência, do espaço dessa cidade não nomeada aos aspectos da cidade de Santa Fe, lugar de origem do escritor e capital da província argentina de mesmo nome. De fato, os elementos espaciais da obra de Saer (disposição dos caminhos e lugares, endereços, distâncias e trajetos) podem encontrar sua referência na cidade real de Santa Fe, cidade essa que não aparece nunca nomeada no conjunto de sua ficção, ao passo que 


\section{4 | Iuri Almeida Müller}

as demais localidades (Buenos Aires, Rosario, Paris, etc.) são, no entanto, mencionadas pelo nome ao longo dos textos.

A aproximação da ficção com o real e a problemática da nomeação exigem, por certo, discussões de outro fôlego, mas a ressalva mais importante, para situar as intenções analíticas e críticas, já foi apontada por Premat em La dicha de Saturno: "El sentido de la elección de ese espacio-tiempo es [...] absolutamente claro: se trata de instaurar un espacio cuya literariedad no se preste a discusión, dejando de lado [...] toda ilusión referencial, todo realismo” (2002, p. 183). Para Premat, por fim, "así se define el lugar de la literatura: a medio camino entre lo real (la ciudad concreta, existente, a orillas de un río cuyas aguas mojan de verdad, y la imaginación (la fábula sin puntos de referencia)" (2002, p. 183), e encontra nas poéticas de William Faulkner e Juan Carlos Onetti correspondências do projeto e das intenções de Juan José Saer.

Entre Glosa e Lo imborrable, a cidade saeriana é o espaço que permite a aparição de um trânsito de duas mãos: dos deslocamentos de um texto a outro, a movimentar a intertextualidade interna à obra, e dos trajetos que acontecem no corpo do texto, nas caminhadas que se expandem e encontram o núcleo dessa ficção.

\section{REFERÊNCIAS}

KOHAN, M. Glosa, novela política. In: RICCI, P. Zona de prólogos. Buenos Aires: Seix Barral, 2011.

ONETTI, J. C. Novelas cortas. Cordoba: Alción, 2009.

PREMAT, J. La dicha de Saturno. Escritura y melancolía en la obra de Juan José Saer. Rosario: Beatriz Viterbo, 2002.

SAER, J. J. Cuentos completos. Buenos Aires: Seix Barral, 2012.

SAER, J. J. El limonero real. Buenos Aires: Seix Barral, 2006.

SAER, J. J. Glosa. Buenos Aires: Seix Barral, 1995.

SAER, J. J. Lo imborrable. Buenos Aires: Seix Barral, 2003.

SARLO, B. Escritos sobre literatura argentina. Buenos Aires: Siglo XXI, 2007.

Recebido em: 22/08/2019

Aceito em: 14/09/2019 